\title{
Understanding the Marginalized in the Mainstream: Teacher Education and Aboriginal Educational Policy in Ontario (Canada)
}

\author{
Lorenzo Cherubini, Ed.D. \\ Associate Professor, Faculty of Education \\ Director of the Tecumseh Centre for Aboriginal Research \\ Brock University \\ 1842 King Street East, Hamilton, Ontario L8K 1V7, Canada \\ Tel: 1-905-547-3555Ｅ-mail: Lorenzo.cherubini@brocku.ca
}

Received: December 22, 2010 Accepted: January 9, 2011 Published: October 12, 2011

doi:10.5296/ije.v3i2.534 URL: http://dx.doi.org/10.5296/ije.v3i2.534

\begin{abstract}
This study investigates the perceptions of elementary school teachers and principals in two publicly-funded school boards in northern Ontario, Canada, with high populations of Aboriginal students. A mixed-methods research design was used to examine participants' perceptions of the effectiveness of both their pre-service and continuing education programs in preparing them to address the key aspects of Aboriginal elementary students' bi-cultural and epistemic needs in mainstream public schools in light of recent policy contexts. Participants reported that their pre-service and continuing education were less than effective in preparing them to address Aboriginal students' bi-cultural and epistemic needs.
\end{abstract}

Keywords: Indigenous students, Teacher perception, Epistemology, Public policy 


\section{Introduction}

Aboriginal peoples across North America and beyond have endured rather despairing experiences with formal education as a result of colonization that has translated into poorer social, psychological, physical, and even spiritual outcomes (Halloran, 2006; Reynolds, 2001). Many government initiatives in various countries have implemented policies to reconcile the difficulties Aboriginal students experience in public educational institutions (Clancy \& Simpson, 2002; Buckskin, 2000). There have been a number of initiatives on the part of the Ontario Ministry of Education (OME) in Canada to improve the educational experiences of Aboriginal students in mainstream public schools. In Ontario, the Aboriginal population grew from 188,315 to 242,495 representing a nearly 30\% increase between 2001 and 2006. (It should be noted that Section 93 of the Constitution Act, 1867, states that education is a provincial responsibility in Canada, with the exception of reservation schools that fall under Federal jurisdiction). Various policy initiatives related to Aboriginal education address the difficulties that Aboriginal students have achieving educational levels that are comparable to mainstream Canadian students. Among these initiatives are: The Ontario First Nation, Métis, and Inuit Education Policy Framework (2007), Many Roots, Many Voices (2005), and Building Bridges to Success for First Nation Métis and Inuit Students (2007).

The policy contexts from which these initiatives emerge recognize the adverse social and political implications that educational institutions and practices have had on Aboriginal learners. The reality is that the state of education for Aboriginal youth in Ontario is in crisis; according to the OME, the rate of Aboriginal students who drop out of school is on average twice as high as the mainstream population. The various policy documents, therefore, recognize Aboriginal students' unique learning needs and outline specific pedagogical strategies for teachers to implement in their classrooms that are reflective of Aboriginal students' holistic and integrated approach to learning. The policies also underscore the importance of school culture to create invitational and meaningful learning environments for the over 50,000 Aboriginal students and their communities enrolled in public education across the province (Ontario Policy Framework, 2000). The policies state that the province's teachers, principals and school board administrators will recognize Aboriginal students' distinct cultural and epistemic traditions, while actively informing their pedagogy to improve Aboriginal student academic achievement. An intent of the policy frameworks is to heighten teachers' and administrators' awareness of Aboriginal students' social, cultural, and academic preferences in order for educators to authentically represent Aboriginal students' knowledge, traditions, and cultural nuances into the social fabric of their classrooms and schools (Cherubini, 2010). Research suggests that schools that create learning environments that respect and include Aboriginal students' socio-cultural and socio-linguistic world views both strengthen their sense of identity and improve their academic achievement (Hilberg \& Tharp, 2002; Kanu, 2002; Swanson, 2003).

\subsection{Purpose of the Paper}

The studies on which this paper is based attempt to understand the perceptions of elementary school teachers and principals in two publicly funded school boards in northern Ontario, Canada, with high populations of Aboriginal students. More specifically, this study employed 
a mixed-methods research design to examine participants' perceptions of the effectiveness of both their pre-service and continuing education programs in preparing them to address the key aspects of Aboriginal elementary students' bi-cultural and epistemic needs in mainstream public schools.

\section{Theoretical Framework}

The following theoretical framework informed the analysis and interpretation of the data.

\subsection{Teacher Education}

The circumstance of White middle class mainstream educators teaching in multicultural schools is not unique to Ontario, Canada, the United States, and even overseas (LeCompte \& McCray, 2002; Santoro \& Allard, 2005). While the demographics of the teaching profession in North America and Europe remains relatively unchanged, student populations are becoming more diverse (Basit, Roberts, McNamara, Carrington, Maguire \& Woodrow, 2006; Leavy, 2005; Luciak, 2006). Prospective teachers enrolled in formal teacher education programs do not in many instances have a genuine understanding of student cultures when they differ from their own; thus, some teacher education programs include multicultural education modules or courses that seek to develop student-teachers' knowledge about various ethnic groups (Santoro, 2007). Research suggests, however, that White mainstream teachers in many instances lack the self- awareness of their own ethnic and epistemic privileges and biases (Causey, Thomas, \& Armento, 2000; Cockrell, Placier, Cockrell, \& Middleton, 1999). In this light, teacher education programs,

Generally focus on imparting targeted knowledge and conceptions of teaching along with skills. Research has demonstrated, however, that teachers and prospective teachers come to the encounter with the educational and curricular program with pre-existing and quite stable contents and pedagogical beliefs and ideology. These beliefs and ideology are personal and very difficult to change. (Shkedi \& Nisan, 2006, page 689)

Effective teaching, however, entails a culturally sensitive pedagogy of diverse instructional strategies to engage the multifaceted learning needs of all students (Ladson-Billings, 1994; LeRoux, 2001). As Boyer (1996), Hollins (1995) and Marshall (1996) have argued for well over a decade, teacher education programs need to foster a deep understanding in student-teachers of cultural norms other than their own. This begins with the critical examination of their own attitudes, knowledge, and epistemologies (Author). Effective pre-service teacher education programs introduce prospective teachers to not only the theoretical implications of teaching diverse student populations, but to an assortment of instructional techniques to engage all students in experiential learning.

There are a number of implications for Aboriginal students specifically when student-teachers' preconceptions of teaching are left unchallenged by teacher educators (Britzman, 1991). The literature suggests that student-teachers' preconceptions of teaching and learning are generally unexamined (Kukari, 2004). In these instances, prospective teachers perpetuate the assumptions related to teacher and student roles and western notions 
of knowledge-construction. Teaching, from a traditional Eurocentric perspective, is based on predefined knowledge as it presented in prescribed text books. A teacher's role, as the possessor of knowledge, is to convey the knowledge unto the students. Students, in turn, absorb and memorize the pre-selected externally identified facts and values. Based on a power relationship, the teacher possesses the knowledge and the power situating the student as a rather passive recipient since they do not have the required knowledge (Kukari, 2004). The traditional teacher-directed instructional approach, however, does not cater to the unique identity of Aboriginal learners (Jacobs \& Reyhner, 2002; Kleary \& Peacock, 1998). It should be noted that such traditional direct instructional practice does not necessarily engage non-Aboriginal learners either. Further to the above, prospective teachers must become sensitive to the development of certain dispositions toward Aboriginal students and ideologies:

Affective qualities, rather than skills or academic preparation, seem to characterize effective teachers in the research literature. Studies indicate that teachers who serve Native students effectively are informal, are caring and warm, give up authority, and have and show respect for the students. (Yazzi, 1999, p. 95)

Among the recommended pedagogical techniques for teaching Aboriginal learners includes co-operative learning (Demmert, 2001), visual learning (Sparks, 2000) and holistic approaches that account for Aboriginal students' worldviews (Klug \& Whitfield, 2003).

\subsection{Teacher Professional Development}

Just as it is imperative to raise the critical consciousness of prospective teachers through pre-service education, so too the literature advocates for continuing professional education opportunities for teachers in order to foster sustainable change in mainstream schools and improve the educational experiences of Aboriginal youth (Castagno \& Jones-Brayboy, 2008). Professional development opportunities cannot restrict themselves to engaging participants in issues of diversity (Cope \& Kalantzis, 1999) but must aim to "develop an understanding of power and inequality, played out in situated interactions and everyday relationships” (D’Cruz, 2007, p.41). Opportunities to endorse teachers' professional development of issues related to equity are often unsuccessful when unaccompanied by a lack of resources and the infrastructure necessary to support them (Hewitt, 2000; Reynolds, 2002). Such a lack of support hinders teachers from making the necessary connections in the context of Aboriginal students' socio-cultural and epistemic traditions (Glynn, Wearmouth, \& Berryman, 2005; Gregory, Long, \& Volk, 2004), and does not provide them with the necessary expertise to tailor their practice in a culturally-responsive manner (Wearmouth, Glynn, \& Berryman, 2005). Professional development opportunities must account for the varying stages of teachers' and school administrators' careers, their professional experiences, and their interest in broadening their perspectives to meet the mandate of the policy initiatives.

Above and beyond these considerations, professional development training must recognize the demands of time that are often transferred upon teachers' workloads when public 
education policy is introduced. The literature recognizes that teachers and school administrators have little time to engage in professional development given the expectations of curriculum, the responsibilities of assessment and evaluation, and their broadening roles (Hirst \& Vadeboncoeur, 2006; Smyth, 2001). This is particularly challenging when considering the nature of the paradigm-shift necessary for educators to first challenge their own epistemic and socio-cultural assumptions and positions of privilege, and then account for the unique identity of Aboriginal thought and worldviews. The literature suggests that mainstream teachers and principals must come to know that multiple epistemologies exist and that their students may come to school with a very different worldview than they themselves have grown up with. Particularly in the context of the OME policy Framework, educators are commissioned to adopt pedagogy to suit the educational aims of Aboriginal students. Multiple epistemologies can and must co-exist within school settings (Jacobs \& Reyhner, 2002), and Aboriginal youth are more likely to be better served by integrating multiple epistemologies into teachers' pedagogy, curricula, and school cultures (Castagno \& Brayboy, 2008). In fact, the same pedagogical strategies recommended as being effective for Aboriginal students are often successful tactics for all students (Hilberg \& Tharp, 2002) and thus teachers and principals,

Need to study alternative epistemologies, multiple perspectives, and critical multicultural pedagogies, including both-ways curricula, which would lead them to different ways of educating. They need to experiment with the difficult task of creating alternative curricula and pedagogical approaches that not only rock the boat but ultimately overturn the boat of the traditional curriculum grounded in the dominant culture of unexamined whiteness. (Hickling-Hudson \& Ahlquist, 2003, p.89)

Effective teaching requires educators to value and understand their students both within and beyond the walls of the classroom (Gay, 2002).

\section{Methods}

The study's mixed-methods research design included quantitative and qualitative data to provide a more comprehensive understanding of the research (Creswell \& Plano-Clark, 2002; Tashakkori \& Teddlie, 2003). This research study addresses the gap in the research literature as it relates to investigating educators' perceptions, as those in the front lines of the classrooms and schools, of Aboriginal students' experiences in public education.

\subsection{Participants}

School board selection was based on the high population of Aboriginal students in two boards located in northern Ontario, Canada, wherein nearly $10 \%$ of the population is Aboriginal and half of whom are below 24 years of age (Census, 2006). The selected school boards service a vast geographical region and have a formal Aboriginal education cultural program available to students. The school boards include seven Aboriginal tribal councils. Sixty-three elementary school educators participated in this study, including twenty-six principals, thirteen intermediate teachers (grades 7 to 8), twelve junior teachers (grades 4 to 6) and 
twelve primary division teachers (grades 1 to 3 ). It should be noted that all of the principal participants received preservice training that was the same as the teacher participants.

Purposive sampling of participants addressed a balanced representation of sex, years of experience as teachers and principals and grade division. Principal participants represented $41 \%$ of the total sample $(\mathrm{N}=26) .8 .8 \%$ of the principals had less than one year experience as a principal; $42.3 \%$ had between 1 to 4 years of experience; 23\% reported to have 5 to 10 years of experience, and 30.7\% indicated having more than 10 years of experience in the role of administrator. Primary-level teachers represented $19 \%$ of the total study sample $(\mathrm{N}=12)$. $8 \%$ indicated 1 to 4 years experience in their role as primary teacher; 33\% had between 5 and 10 years experience and 58\% had more than 10 years of experience. Junior-level teacher participants also represented $19 \%$ of the total population of this study $(\mathrm{N}=12) .8 \%$ reported to have less than one year experience; 25\% had between 1 and 4 years of experience; 25\% indicated having between 5 and 10 years experience, while 42\% reported being in their role for more than 10 years. Intermediate-level teachers represented $20.6 \%$ of the total sample $(\mathrm{N}=13)$. 23\% of participants had between 1 and 4 years of experience; $54 \%$ reported to have between 5 and 10 years; while 23\% indicated to have more than 10 years of experience as an intermediate teacher. Participant selection also ensured school district representation. This was particularly significant given the fact that the two school boards encompass widely dispersed urban and rural school communities. The participants as a sample represent the school boards fairly reasonably. Three percent of the participant responses were discarded during the initial analysis due to response prevarication.

The survey was field tested under similar circumstances with different samples of elementary school teachers and principals from other boards of education in Ontario for the sake of instrument fidelity (Onwuegbuzie, Witcher, Collins, Files, Wiedmaier, \& Moore, 2007). Debriefing sessions were held after each field test to offer a further external evaluation (Maxwell, 2005). The mixed-method design lent itself to a more descriptive analysis of educators' perceptions of issues related to Aboriginal student education and provided further validation to its results. Two colleagues, both of whom are Aboriginal scholars, constructively criticized the findings as they were interrogated throughout the data analysis (Lincoln \& Guba, 1985).

\subsection{Procedure}

The mixed-methods research design compared participants' survey responses with their more detailed qualitative responses to an open-ended question. The process allowed for the concurrent collection but separate analysis of the quantitative and qualitative data (considered for the purpose of this analysis to have equal weighting) before the amalgamation of the two data sets during the interpretation phase of the study (Creswell, Plano-Clark et al, 2003; Hanson et al, 2005).

The quantitative component consisted of six statements that required participants to respond to a Likert-type scale ranging from strongly disagree (1) to strongly agree (5). The statements were listed as follows: 
1. My pre-service teacher education program prepared me to address the bi-cultural needs of Aboriginal students.

2. My pre-service teacher education program prepared me to meaningfully represent Aboriginal students' values and worldviews in my teaching.

3. My pre-service teacher education program encouraged me to examine my own biases and dispositions in terms of my teacher identity and teaching practice.

4. As a result of various school board or school initiatives, I am able to adopt a variety of instructional methods to teach Aboriginal students effectively.

5. As a result of various school board or school initiatives, I have developed an awareness of the learning styles of Aboriginal students.

6. As a result of various school board or school initiatives, I am able to implement a variety of assessment strategies to evaluate Aboriginal students effectively.

Participants then had the opportunity to elaborate upon their thoughts by commenting on an open ended question that was stated:

1. Describe in detail the kinds of bicultural identity issues that the Aboriginal students in your classroom / school find most challenging.

A definition of "bilcultural identity issues" was provided to enable participants to elaborate upon their responses. Given that bicultural identity was the core subject inherent in the Likert scale questions, the open-ended question was intended to allow participants to elaborate upon their thoughts that may not have been represented in the quantitative section.

The electronic survey was administered in December 2008 and remained open to participants until February 2009. Each participant was provided with a confidential username and password to access the on-line site and complete the survey. Responses were stored securely in a central data bank to which only the researcher had access. In advance of the survey distribution, the respective supervisory officers from both school boards were provided with a description of the study.

\subsection{Data Analysis}

The Likert-scale responses were quantitatively analysed for means and frequencies. T-tests analysed the differences along the following multiple comparisons: (1) teacher versus administrator (2) teachers by division taught, and (3) across the number of years of teaching experience. The findings are tabled in the Results section.

The open ended responses were analysed according to grounded theory. Grounded theory is a qualitative mode of analysis that involves the multiple coding of respective patterns that emerge from the data (Glaser \& Strauss, 1967). The patterns were collapsed into a core category through the process of constant comparison (Strauss \& Corbin, 1990). Constant comparison accounts for the conceptual relationships of the themes as they are identified throughout the analysis. 


\section{Results}

The results from the quantitative and qualitative analysis are presented separately. The primary findings of this study were threefold: One, the principal and teacher participants reported that their pre-service teacher education and continuing education programs were less than effective in preparing them to address the key aspect of Aboriginal elementary students' bi-cultural and epistemic needs in mainstream public schools. Two, insignificant relationships were discovered consistently regarding the ineffectiveness of their preparation and continuing education across all participant cohorts. Third, the realities of educators' perceived lack of preparation has serious implications for both their pedagogy and understanding of Aboriginal student's worldviews.

\subsection{Quantitative Results}

The descriptive means for the first question across all four participant cohort groups (principals, primary, junior, and intermediate teachers), ranged from 2.00 (primary) to 2.43 (intermediate). There was a standard deviation of 1.34 and 1.22 respectively. This represents the lowest range of differences in mean scores across all six questions (0.43). The total mean score for this question that surveyed participants' perception of the effectiveness of their pre-service education programs to address the bi-cultural needs of Aboriginal students was 2.18 (with 1.19 standard deviation).

The second question, surveying participants' perceptions of their pre-service education programs effectiveness to meaningfully represent Aboriginal students' values and worldviews in their pedagogy, resulted in a mean range of 1.96 (principals) to 2.43 (intermediate), with a standard deviation of 1.04 and 1.22 respectively. The total mean across all cohorts was 2.19 (with a 1.19 standard deviation).

In response to the third question, that asked participants to assess the effectiveness of their pre-service program to encourage them to examine their epistemic bias in light of their practice and professional identity, the total mean score was 2.87 (1.3 standard deviation) including a mean range of 2.67 (primary) - 1.4 standard deviation - to 3.4 (intermediate 1.08 standard deviation).

The total mean for the fourth question was 3.66 (standard deviation of 0.91). This question asked participants to rate the effectiveness of school board continuing education initiatives in terms of developing educators' proficiency in adopting a variety of instructional strategies to teach Aboriginal students effectively. The mean range for this question was 3.27 (primary-0.88 standard deviation) to 4.14 (intermediate - standard deviation of 0.54 ).

The fifth question asked participants to rate the effectiveness of school board or school initiatives offering continuing education in terms of fostering their awareness of the learning styles of Aboriginal students. The total mean score was 3.78 (0.94 standard deviation) and represented the highest total mean of all responses. The range between means also represented the highest value reported to be from 3.33 (junior teachers - 1.2 standard deviation) to 4.21 (intermediate teachers- 0.58 standard deviation). 
The final question surveyed participants to determine the effectiveness of continuing education opportunities offered by their school board and school in light of furthering their proficiency in implementing a variety of assessment strategies to evaluate Aboriginal students effectively. The total mean score was 3.21 (standard deviation 1.09). The range of mean scores was from 2.8 to 3.6 (1.2 and 1.08 standard deviation respectively) representing 0.84 difference. The intermediate teacher cohort accounted for the highest mean of all the cohorts in every question. (See Table 1).

Table 1. Descriptive means for likert-scale statements

\begin{tabular}{|c|c|c|c|c|c|c|}
\hline Statement & PC & $\mathbf{N}$ & Mean & SD & SE & $\mathbf{R} / \mathbf{M}$ \\
\hline $\begin{array}{l}\text { My professional teacher education program } \\
\text { prepared me to address the bi-cultural needs of } \\
\text { Aboriginal students. }\end{array}$ & $\begin{array}{l}\text { Primary } \\
\text { Junior } \\
\text { Interm. } \\
\text { Principals } \\
\text { Total }\end{array}$ & $\begin{array}{l}12 \\
12 \\
13 \\
26 \\
63\end{array}$ & $\begin{array}{l}2.00 \\
2.25 \\
2.43 \\
2.12 \\
2.18\end{array}$ & $\begin{array}{l}1.36 \\
1.13 \\
1.22 \\
1.14 \\
1.19\end{array}$ & $\begin{array}{l}.352 \\
.329 \\
.327 \\
.224 \\
.146\end{array}$ & .43 \\
\hline $\begin{array}{l}\text { My professional teacher education program } \\
\text { prepared me to represent Aboriginal students' } \\
\text { values and worldviews in my teaching. }\end{array}$ & $\begin{array}{l}\text { Primary } \\
\text { Junior } \\
\text { Interm. } \\
\text { Principals } \\
\text { Total }\end{array}$ & $\begin{array}{l}12 \\
12 \\
13 \\
26 \\
63\end{array}$ & $\begin{array}{l}2.20 \\
2.42 \\
2.43 \\
1.96 \\
2.19\end{array}$ & $\begin{array}{l}1.37 \\
1.31 \\
1.22 \\
1.03 \\
1.19\end{array}$ & $\begin{array}{l}.355 \\
.379 \\
.327 \\
.204 \\
.146\end{array}$ & .47 \\
\hline $\begin{array}{l}\text { My professional teacher education program } \\
\text { encouraged me to examine my biases \& } \\
\text { dispositions. }\end{array}$ & $\begin{array}{l}\text { Primary } \\
\text { Junior } \\
\text { Interm. } \\
\text { Principals } \\
\text { Total }\end{array}$ & $\begin{array}{l}12 \\
12 \\
13 \\
26 \\
63\end{array}$ & $\begin{array}{l}2.67 \\
2.83 \\
3.36 \\
2.73 \\
2.87\end{array}$ & $\begin{array}{l}1.39 \\
1.33 \\
1.08 \\
1.21 \\
1.25\end{array}$ & \begin{tabular}{l|}
.361 \\
.386 \\
.289 \\
.239 \\
.153
\end{tabular} & .69 \\
\hline $\begin{array}{l}\text { As a result of various school board / school } \\
\text { initiatives, I can implement a variety of } \\
\text { instructional methods to teach Aboriginal } \\
\text { students effectively. }\end{array}$ & $\begin{array}{l}\text { Primary } \\
\text { Junior } \\
\text { Interm } \\
\text { Principals } \\
\text { Total }\end{array}$ & $\begin{array}{l}12 \\
12 \\
13 \\
26 \\
63\end{array}$ & $\begin{array}{l}3.27 \\
3.33 \\
4.14 \\
3.77 \\
3.66\end{array}$ & $\begin{array}{l}.884 \\
1.15 \\
.535 \\
.863 \\
.914\end{array}$ & $\begin{array}{l}.228 \\
.333 \\
.143 \\
.169 \\
.112\end{array}$ & .87 \\
\hline $\begin{array}{l}\text { As a result of various school board / school } \\
\text { initiatives, I have developed an awareness of } \\
\text { the learning styles of Aboriginal students. }\end{array}$ & $\begin{array}{l}\text { Primary } \\
\text { Junior } \\
\text { Interm. } \\
\text { Principals } \\
\text { Total }\end{array}$ & $\begin{array}{l}12 \\
12 \\
13 \\
26 \\
63\end{array}$ & $\begin{array}{l}3.40 \\
3.33 \\
4.21 \\
3.96 \\
3.78\end{array}$ & $\begin{array}{l}1.18 \\
1.15 \\
.579 \\
.662 \\
.935\end{array}$ & $\begin{array}{l}.306 \\
.333 \\
.155 \\
.130 \\
.114\end{array}$ & .88 \\
\hline $\begin{array}{l}\text { As a result of various school board / school } \\
\text { initiatives, I am able to implement a variety of } \\
\text { assessment strategies to evaluate Aboriginal } \\
\text { students effectively. }\end{array}$ & $\begin{array}{l}\text { Primary } \\
\text { Junior } \\
\text { Interm. } \\
\text { Principals } \\
\text { Total }\end{array}$ & $\begin{array}{l}12 \\
12 \\
13 \\
26 \\
63\end{array}$ & $\begin{array}{l}2.80 \\
2.83 \\
3.64 \\
3.38 \\
3.21\end{array}$ & $\begin{array}{l}1.20 \\
1.03 \\
1.08 \\
.983 \\
1.09\end{array}$ & $\begin{array}{l}.312 \\
.297 \\
.289 \\
.193 \\
.134\end{array}$ & .84 \\
\hline
\end{tabular}

PC: Participant Cohort; N: Number of Participants; SD: Standard Deviation; SE: Standard Error; R/M: Range of Mean Scores 


\section{Test of Significant Differences: Post Hoc Bonferroni}

The data was subjected to a Post Hoc Bonferroni repeated measure at a 0.05 significance level. Participants' responses on all six survey questions were compared based on (1) their divisional or administrative role and (2) their years of experience in their current role. In all comparisons only one significant difference resulted. There was a significant difference between the primary and intermediate teacher cohorts in response to question four (the effectiveness of continuing education programs to assist educators in adopting a variety of culturally relevant instructional methods) at a significance level of 0.053 (with a 0.324 standard error). (See Table 2).

Table 2. Test of significant differences: Post-hoc Bonferroni (0.05 alpha level)

\begin{tabular}{|c|c|c|c|c|}
\hline Statement & PC & PC & Sig. & SE \\
\hline $\begin{array}{l}\text { As a result of various school board } \\
\text { / school initiatives, I can } \\
\text { implement a variety of } \\
\text { instructional methods to teach } \\
\text { Aboriginal students effectively. }\end{array}$ & Primary & Interm & .053 & .324 \\
\hline
\end{tabular}

PC: Participant Cohort; Sig.: Significant Difference; SE: Standard Error

\subsection{Qualitative Results}

Using the tenets of grounded theory, various categories emerged from the qualitative data of each of the participant cohorts' descriptions of the bi-cultural identity issues that Aboriginal students find most challenging. The respective four categories from the elementary school cohort consisted of: (1) Principals' lack of awareness of issues (2) Lack of relationships between Aboriginal students (3) Insignificant representation of Aboriginal culture in school artifacts, and (4) School celebrates all cultures. Emerging from the primary-level teacher cohort were the following three categories: (1) Significant impact of domestic issues on Aboriginal students (2) Struggles with literacy and numeracy, and (3) Aboriginal students' withdrawn nature. In terms of the junior-level teachers, the categories were identified as: (1) Lack of teacher knowledge to address the topic of Aboriginal students' struggle with bi-cultural identity (2) Little cultural support in the school, and (3) No awareness of any issues. Last the categories that emerged from intermediate-level teacher cohort data consisted of the following: (1) Insignificant cultural space in the school (2) Difficulties with oral and written English (3) Students' reluctance to conform, and (4) All cultural identities are accepted in the school.

Using the process of constant comparison, the above categories and their respective properties were collapsed into three core categories across all participant cohorts (Author). The core categories that were grounded in participants' reflections and that will be elaborated upon in this section were identified as: (1) Non-existent challenges (2) Curricular challenges, and (3) Living in an indeterminate state. The responses cited in the body of the Results section represent what the researcher considered to be key statements towards the identification of the core categories. Principals' contributions are identified as (Prin); the 
primary-level teachers' as (Prim); the junior-level teachers as (Jr); and the intermediate-level teachers as (Interm).

\subsection{Non Existent Challenges}

Various participants stated that they were not aware of any bi-cultural identity issues that Aboriginal students were challenged with in their schools and classrooms. Typical of other principals, one individual wrote, "There have never been issues with bi-cultural identity expressed by Aboriginal students or their parents" (Prin 6). Similarly, another principal admitted, "I am not aware of any issues” (Prin 10). These participants, and others like them, were candid in their responses that issues of bi-cultural identity did not exist for Aboriginal students in their school. A different administrator suggested that because there were relatively few Aboriginal students in the school, "there are no bi-cultural identity issues" (Prin 11). Whether it was a result of low number of Aboriginal student representation in the school, or a result of the fact that their schools "encourage a respectful [and] safe environment where everyone is treated equally" (Prin 14), principals directly attributed and related these observations to the fact that Aboriginal students were not challenged by issues of identity. Couple that with the suggestion, as one principal made, that neither the school nor the school community has ever brought such a challenge to the fore: "I have not encountered any such issues from Aboriginal students in my classrooms or school. If they exist, they have never been indicated by the children and their parents, nor have they been discussed as challenges by the staff" (Prin 55). Principals concluded in many instances that "challenges are nonexistent as we have a multicultural identity respecting all cultures" (Prin 26), and as another principal wrote, "bi-cultural issues are celebrated and addressed in a positive manner” (Prin 38).

The teacher cohorts also reported in many cases of their unawareness of Aboriginal student challenges in their classrooms. Based on their observations of the Aboriginal students in their care, teachers stated that the students "have not expressed or demonstrated in any way what presents a challenge to them in their day-to-day interactions" (Prim 62). Since some teachers were quite candid in reporting that they "are not aware of bi-culture identity issues" (Jr 63), they felt that they could not elaborate upon the various implications associated with being an Aboriginal student attending mainstream public schools governed by mainstream values and traditions. This finding was particularly true for those teachers who reported that more than $20 \%$ of their student population was Aboriginal and in some cases more than $60 \%$ of their student body. As a result, teachers felt that because it was "not evident" in their classrooms, the issue of Aboriginal students being challenged by bi-culture identity was "not seen as being a concern" ( $\mathrm{Jr} 46)$. Like the principal cohort, teacher participants based their conclusion that such challenges did not exist in their classrooms on the fact that "they have not indicated any problems or issues” to their teachers (Interm 53). Teacher participants identified the fact that these issues may not exist because, as one intermediate teacher participant described, "We have a very diverse population of students and teachers who are extremely sensitive to and accepting of all the individual differences among people in our school” (Interm 65). These educators did not distinguish Aboriginal student challenges with bi-cultural identity from the other diverse student populations in their classrooms and schools. Their responses 
captured the sentiment that respecting all students' diversity reconciles the identity challenges for all students.

\subsection{Curricular Challenges}

Emerging from the data across all participant cohorts was the challenge Aboriginal students faced with the Ontario provincial curriculum. A number of principals described Aboriginal students' struggle with fundamental language conventions that often hindered their proficiency in writing. Aboriginal students, according to this participant cohort, also had difficulty articulating themselves largely as a result of their unfamiliarity with the written word. Typical of others, this principal stated "some of the Aboriginal students in our school struggle with both oral and written standard English language. We encourage our students by providing lots of opportunities for oral discussion and then move towards the written” (Prin $57)$.

Similarly, the teacher cohorts readily described Aboriginal students' curricular challenges. Regardless of their being primary, junior, or intermediate teachers, participants reported that the standard provincial curriculum seemed misaligned to Aboriginal students' learning needs and preferences. Representative of other responses, one teacher stated, "I find Aboriginal children in my classroom and school find the curriculum extremely hard to keep up with. We seem to rely heavily on curriculum and meeting curricular expectations but they struggle to keep up and to meet our expectations" (Prim 31). Another primary teacher reported that her students experienced difficulty "making inferences and connections" between the written word and the expressed understanding (Prim 34). Many teachers cited literacy and numeracy as the two areas that challenged Aboriginal students the most. These teachers acknowledged that literacy and numeracy are the fundamental elements of provincial curriculum and as a result are significant impediments to Aboriginal students' academic achievement. Contributing to these curricular challenges, according to teacher participants, is the fact that "print and visual materials do not always depict people of Aboriginal background" (Jr 40) which serves to further disconnect Aboriginal students from the mainstream curriculum given the fact that they are not represented in what they read and see in school. Typical of other teachers, this individual observed, "There is not much in the daily surroundings [including] posters and language activities that Aboriginal students could connect with” (Interm 42). To the majority of teacher participants, it seemed to be a predictable conclusion that Aboriginal students "find written work hard because they find it easier just using the spoken word to tell stories...however they do not like speaking in front of their fellow classmates when doing presentations" (Interm 15).

\subsection{Living in an Indeterminate State}

Principal participants reported that the Aboriginal students in their schools often lack a sense of belonging. Among the most telling responses, one principal participant explained, "We have certain students who talk about not belonging anywhere" (Prin 59). Principals recognized that in many cases Aboriginal students had difficulty being accepted within both the school environment and in their First Nation communities. Other principal participants referred to what one individual described as the "lack of exposure to Aboriginal traditions for 
the rest of the student body" (Prin 37) to explain the lack of cultural understanding that displaces Aboriginal students from the mainstream population. Some participants attributed Aboriginal students' sense of non-belonging to their inability to establish positive relationships. One participant stated, "I do know that many of the students have problems with relationships and addictions. Many of them seek out a gang style mentality most likely to have a sense of belonging with some group” (Prin 7).

Teacher participants too reported Aboriginal students' lack of belonging to the school and school community. Some described the primary students' reactions to Aboriginal boys who have long braids: "Many of the children in junior kindergarten take a long time to accept that the student is a boy and not a girl. The students question why the boy with the braid is not going into the girls' bathroom ... this year [one Aboriginal] student insisted on getting his hair cut short" (Prim 67). Another primary teacher acknowledged the impact of past injustices to explain Aboriginal students' reluctance to feel at ease in school: "I think that often our students are not proud of their family and their history because of all the abuse that has taken place in the past ... acceptance within the [mainstream] culture is a slow process" (Prim 35). Other teachers recognized the difficulties that minority students struggle with in mainstream schools since "when you are a very small minority it is difficult not to feel like an other" (Jr 17). Other teacher participants discussed Aboriginal students' indeterminate state in their classrooms in the context of their being,

In split homes where one parent is Aboriginal and the other is not. The student's identity changes depending on what household he or she is in and thus they have very little sense of self...little in the way of cultural support [in the school] they are further lost in the shuffle to find themselves and connect. (Jr 51)

Some teachers commented that Aboriginal students' sense of self is not affirmed in their school as there is "little of their culture represented" (Interm 42) and they do not readily "see many Aboriginal role models in the school on a regular basis” (Interm 58). Still other teacher participants refer to the lack of space in the school for Aboriginal students to meet and bond. These participants suggested that Aboriginal students' fragile sense of identity is often not nurtured by a distinguished place in the school to which they can specifically identify. An intermediate teacher explained it this way: "They need a space to hang out and share with others what and how they are doing ... a space that is not challenging or foreign” (Interm 60).

\section{Discussion}

Both the quantitative and qualitative results contribute to similar conclusions; namely, participants report to feeling unprepared and ill-equipped to properly address Aboriginal students' bi-epistemic needs. The results pose a number of genuine implications for teachers and principals alike on the practice and understanding of Aboriginal students' bi-cultural needs and identity.

To begin, the low total mean scores of all cohort groups throughout the six Likert-scale responses are notable. At best, participants' responses represented a mean of 3.78 (for question 5); far from a convincing response when one considers that three on the scale was 
defined as "indifferent". Considered further, the mean score to this question indicated that school board or school continuing education initiatives were the most effective (in comparison to the other 5 questions) in terms of developing educators' awareness of the learning styles of Aboriginal students - yet such an effectiveness was reported as having merely an indifferent effect. The mean of the first three questions were in the 2 scale range; thus participants disagreed that their pre-service education programs were effective in preparing them to address Aboriginal students' needs, represent Aboriginal values in the school, and in encouraging them to examine their own bias as prospective teachers. Dei and Calliste (2000), and Levine-Rasky (1998), among others, argue that pre-service teacher education should challenge mainstream teachers' paradigms from a broader social context so that they are equipped to recognize the needs of marginalised students. Participants responses indicate that teacher education has not effectively prepared teacher candidates to plan, deliver, and assess for Aboriginal student learning in their classrooms and schools.

The lack of self reported perceived competency on the part of teachers and principals would seem to hinder Aboriginal student socio-cultural engagement and academic success. Participants are unable to draw upon a range of responses to positively influence Aboriginal students as they would for the mainstream students. It is not surprising that some participants admitted that they struggle trying to establish a relationship with their Aboriginal students. One participant admitted that the students' "quiet mannerisms and seemingly withdrawn nature makes [them] difficult to reach” (Prim 25). Given that educators do not feel adequately prepared to foster Aboriginal student engagement, they admitted to having difficulties in regards to managerial issues as well: "It is difficult dealing with behavioural problems with our Aboriginal students due to a lack of knowledge of their culture" (Jr 30). The results of the study further compliment the literature that states that teacher education programs in North America generally do not address teacher candidates' awareness, knowledge, and capacities of what it means to be a culturally responsive teacher (Castagno \& Jones-Brayboy, 2008; Diller \& Moul, 2005).

In terms of continuing education and professional development initiatives, participants' scores indicate their indifference to any effect such initiatives may have had in terms of improving educators' proficiencies to cater their teaching to Aboriginal students' learning styles and preferences. Given the emergence of The Ontario First Nation, Métis, and Inuit Education Policy Framework (2007), one may have expected these results to have been different. The policy Framework includes specific strategies for teachers, schools, and school boards that are culturally responsive to Aboriginal students:

The strategies outlined in this framework are based on a holistic and integrated approach to improving Aboriginal student outcomes. The overriding issues affecting Aboriginal student achievement are a lack of awareness among teachers of the particular learning styles of Aboriginal students, and a lack of understanding within schools and school boards of First Nation, Métis, and Inuit cultures, histories, and perspectives. (Ontario Policy Framework, 2007, p. 6)

According to the results of this study, educators admit to feeling "ill-equipped to answer or 
support individual student's growth questions” (Jr 51).

The fact that only one significant relationship was identified in the comparative statistical analyses suggests that aside from the primary and intermediate teacher cohorts, there is no difference in participants' experiences and perceptions of the effectiveness of their pre-service preparation and continuing education to address Aboriginal students' epistemic needs and worldviews. Not even the administrator participant cohorts' responses were significantly different than the elementary teachers. Years of experience in the role were essentially inconsequential. Whether a teacher or principal had less than one year or more than 10 years of experience, no significant differences existed in their perceptions of pre and in-service professional development.

The realities of educators feeling ill-prepared to address Aboriginal students' bi-epistemic needs and learning styles has serious implications for their pedagogy and on their level of understanding. For example, principals assumed that because bi-cultural issues and challenges were not reported to them by Aboriginal students, parents, and in some cases teachers, they did not exist. In many cases principals suggested that very few Aboriginal students chose to self identify themselves as Aboriginal in the first place. As one principal deduced, "only 6 students out of 200 have self identified. As such, bi-cultural identity issues do not surface with any real frequency" (Prin 54). Similarly, teachers across all three divisions reported in many instances that they were not aware of any bi-cultural identity issues. Yet, their colleagues made a reference to the manner by which "students from Aboriginal descent find it difficult to adhere to guidelines and often prefer to change the instructions of their teachers to suit their own needs" (Interm 51). Other participants referred to the obvious difference between Aboriginal students and "other cultures" in terms of "routines, time lines and values put on marks" (Interm 68).

In various accounts these differences have not been understood by participants to translate into potentially profound challenges of Aboriginal students' bi-cultural identities. Instead, educators reported that their classrooms and schools equally honoured the uniqueness of all cultures. In these cases participants defended their position by suggesting that no one culture was privileged over another. This response to school environments that are characteristic of racial and ethnic diversity is referred to as "colour blindness" (Cochran-Smith, 1995; McLaren \& Torres, 1999). As the literature suggests, educators who are sensitive towards distinguishing certain identities default to seeing all students in one common light. Sleeter (1993) stated that colour blindness is a myth to which White teachers in particular resort to avoid potentially controversial equity and diversity issues. Difference is, according to Solomon and Levine-Rasky (2003), "an erasable feature of social identity for some teachers because it insults their sense that their primary function is to assimilate students to the Canadian way of life” (p. 23).

\section{Conclusion}

The combined results of this study attest to a poignant implication. Principals and teachers cite the curricular challenges expressed by Aboriginal students, yet report in many instances that no significant bi-epistemic and identity issues exist for Aboriginal students in their 
schools. Participants also reported that neither their pre nor continuing education and professional development have been effective in equipping them to help Aboriginal students mediate these challenges. At no fault of their own, therefore, educators are seemingly resigned to plan for, deliver, and evaluate Aboriginal students according to their unchallenged assumptions of what it means to teach and learn. By not adopting a critical consciousness of culturally responsive pedagogy and teacher and student identity, educators unintentionally perpetuate the same epistemic practices that have marginalised Aboriginal students in varying degrees for over 200 years. This not only privileges the mainstream culture in terms of teacher practice and student achievement, but it also underpins the fact that educators do not recognize their own agency to positively respond to Aboriginal students' epistemic and identity needs.

Both pre and continuing teacher education and professional development appear to need to have a more significant effect on teacher and administrators' awareness and capacity-building to better serve the needs of Aboriginal students. A critical awareness of the socio-historical and socio-cultural realities of Aboriginal peoples needs to be a fundamental component of teacher education from the undergraduate, pre-service, graduate, in-service, and professional development levels. An outcome of these educational interventions would include equipping educators with a more informed perspective of Aboriginal peoples' worldviews thereby positioning them to be more proactive and positive agents of change.

\section{Acknowledgements}

This work is supported by the Social Sciences and Humanities Research Council of Canada (SSHRC).

\section{References}

Agbo, S. (2001). Enhancing success in American Indian students: Participatory research at Akwasasne as part of the development of a culturally relevant curriculum. Journal of American Indian Education, 40(1), 31-56.

Basit, T., Roberts, L., McNamara, O., Carrington, B., Maguire, M., \& Woodrow, D. (2006). Reasons why minority ethnic trainees withdraw from initial teacher training courses. British Educational Research Journal, 32(3), 387-410. http://dx.doi.org/10.1080/01411920600635411

Boyer, J.B. (1996). Diversity and the transformation of teacher education. Paper presented at the Annual Meeting of the Association of Teacher Educators, St. Louis, MO.

Britzman, D. (1991). Practice makes practice: A critical study of learning to teach. Albany, NY: SUNY Press.

Buckskin, P. (2001). Achievements and challenges in Indigenous education. Unicorn, 27, 5-10.

Castagno, A.E., \& Jones Brayboy, B.M. (2008). Culturally responsive schooling for Indigenous youth: A review of the literature. Review of Educational Research, 78(4), 941-993. 
http://dx.doi.org/10.3102/0034654308323036

Causey, V., Thomas, C., \& Armento, B. (2000). Cultural diversity is basically a foreign term to me: The challenges of diversity for preservice teacher education. Teaching and Teacher Education, 16, 33-45. http://dx.doi.org/10.1016/S0742-051X(99)00039-6

Cherubini, L. (2010). An analysis of Ontario Aboriginal education policy: Critical and interpretive perspectives. McGill Journal of Education, 45(1), 1-32.

Clancy, S., \& Simpson, L. (2002). Literacy learning for Indigenous students: Setting a research agenda. Australian Journal of Language and Literacy, 25, 47-63.

Cleary, L., \& Peacock, T. (1998). Collected wisdom: American Indian education. Boston: Allyn \& Bacon.

Cochran-Smith, M. (1995). Colourblindness and basket making are not the answers: Confronting the dilemmas of race, culture and language diversity in teacher education. American Educational Research Journal, 32(3), 493-522.

Cockrell, K., Placier, P., Cockrell, D., \& Middleton, J. (1999). Coming to terms with diversity and multiculturalism in teacher education: Learning about our students, changing our practice. Teaching and Teacher Education, 355-366. http://dx.doi.org/10.1016/S0742-051X(98)00050-X

Cope, B., \& Kalantzis, M. (1999). Frameworks for cross-cultural intervention. In A. Bastaja (Ed.), Cultural dimensions: Approaches to diversity training in Australia (pp. 6-26). Sydney, Human Rights and Equal Opportunity Commission.

Creswell, J.W., \& Plano Clark, V.L. (2007). Designing and conducting mixed methods research. Thousand Oaks, CA: Sage.

Creswell, J.W., Plano Clark, V.L., Gutmann, M., \& Hanson, W. (2003). Advanced mixed methods research designs. In A. Tashakkori \& C.Teddlie (Eds.), Handbook of mixed methods in social and behavioral research (pp. 209-240). Thousand Oaks, CA: Sage.

D’Cruz, H. (2007). Working with diverse bodies, diverse identities: An approach to professional education about diversity. International Journal of Inclusive Education, 11(1), 35-57. http://dx.doi.org/10.1080/13603110500375457

Dei, G.J.S., \& Calliste, A. (Eds.) (2000). Power, knowledge and anti-racism education. Halifax: Fernwood.

Demmert, W. (2001). Improving schools academic performance among Native American students: A review of the research literature. Charleston, WV: ERIC Clearinghouse on Rural Education and Small Schools.

Demmert, W., \& Towner, J. (2003). A review of the research literature on the influences of culturally based education on the academic performance of Native American students. Portland, OR: Northwest Regional Educational Lab. 
Diller, J., \& Moule, J. (2005). Cultural competence: A primer for educators. Belmont, CA: Thomas/ Wadsworth.

Gay, G. (2002). Preparing for culturally responsive teaching. Journal of Teacher Education, 53(2), 106-117. http://dx.doi.org/10.1177/0022487102053002003

Glaser, B.G., \& Strauss, A. (1967). The discovery of grounded theory: Strategies for qualitative research. Chicago: Aldine.

Glynn, T., Wearmouth, J., \& Berryman, M. (2005). Supporting students with literacy difficulties: A responsive approach. Maidenhead: McGraw-Hill.

Gregory, E., Long, S., \& Volk, D. (2004). A sociocultural approach to learning. In E. Gregory, S. Long., and D. Volk (Eds.), Many pathways to literacy: Young children learning with siblings, grandparents, peers and communities (pp. 6-20). New York and London: Routledge Falmer.

Halloran, M.H. (2006). Indigenous reconciliation in Australia: Do values, identity and collective guilt matter? Journal of Community and Applied Social Psychology, 17, 1-18. http://dx.doi.org/10.1002/casp.876

Hanson, W.E., Creswell, J.W., Plano Clark, V.L., Petska, K.P., \& Creswell, J.D. (2005). Mixed methods research designs in counseling psychology. Journal of Counseling Practice, 39(2), Psychology, 52(2), 224-235.

Hewitt, D. (2000). A clash of worldviews: Experiences from teaching Aboriginal students. Theory into 111-117.

Hickling-Hudson, A., \& Ahlquist, R. (2003). Contesting the curriculum in the schooling of Indigenous children in Australia and the United States: From Eurocentrism to culturally powerful pedagogies. Comparative Education Review, 47(1), 64-89. http://dx.doi.org/10.1086/345837

Hilberg, R.S., \& Tharp, R.G. (2002). Theoretical perspectives, research findings, and classroom implications of the learning styles of American Indian and Alaska Native Students. ERIC Clearinghouse on Rural Education and Small Schools. [Online] Available: http://www.ericdigests.org/2003/alaska.htm. (November 27, 2006)

Hirst, E., \& Vadeboncoeur, J.A. (2006). Patrolling the borders of otherness: Displaced identity positions for teachers and students in schooled spaces. Mind, Culture, and Activity, 13(3), 205-227. http://dx.doi.org/10.1207/s15327884mca1303_4

Hollins, E.R. (1995). Revealing the deep meaning of culture in school learning: Framing a new paradigm for teacher preparation. Action in Teacher Education, 17(1), 70-79.

Jacobs, D., \& Reyhner, J. (2002). Preparing teachers to support American Indian and Alaska Native student success and cultural heritage. Charleston, WV: ERIC Clearinghouse on Rural Education and Small Schools.

Kanu, Y. (2002). In their own voices: First Nations students identify some cultural mediators 
of their learning in the formal school system. Alberta Journal of Educational Research, 48(2), 98-119.

Klug, B., \& Whitfield, P. (2003). Widening the circle: Culturally relevant pedagogy for American Indian students. New York: Routledge.

Kukari, A.J. (2004). Cultural and religious experiences: Do they define teaching and learning for pre-service teachers prior to teacher education? Asia-Pacific Journal of Teacher Education, 32(2), 95-110. http://dx.doi.org/10.1080/1359866042000234205

Ladson-Billings, G. (1994). The dreamkeepers: Successful teachers of African American children. San Francisco: Jossey-Bass.

Leavy, A. (2005). When I meet them I talk to them: The challenges of diversity for preservice teacher education. Irish Educational Studies, 24(2/3), 159-177. http://dx.doi.org/10.1080/03323310500435422

LeCompte, K., \& McCray, A. (2002). Complex conversations with teacher candidates. Perspectives of whiteness and culturally responsive teaching. Curriculum and Teaching Dialogue, 4(1), 25-35.

LeRoux, J. (2001). Effective schooling is being culturally responsive. Intercultural Education, 12(1), 41-50. http://dx.doi.org/10.1080/14675980120033957

Levine-Rasky, C. (1998). Preservice teacher education and the negotiation of social difference. British Journal of Sociology of Education, 19(1), 89-112. http://dx.doi.org/10.1080/0142569980190106

Lincoln, Y.S. \& Guba, E.G. (1985). Naturalistic Inquiry. Beverly Hills, CA: Sage.

Luciak, M. (2006). Minority schooling and intercultural education. Intercultural Education, 17(1), 73-80. http://dx.doi.org/10.1080/14675980500502370

Marshall, P.L. (1996). Multicultural teaching concerns: New dimensions in the area of teacher concerns research. Journal of Educational Research, 89, 371-379. http://dx.doi.org/10.1080/00220671.1996.9941341

Maxwell, J.A. (2005). Qualitative Research Design: An Interactive Approach (2 ${ }^{\text {nd }}$ ed.). Thousand Oaks, CA; Sage.

McLaren, P., \& Torres, R. (1999). Racism and multiculturalism education: Rethinking race and whiteness in late capitalism. In Critical multiculturalism: Rethinking multicultural and antiracist education, ed. (pp. 42-76). Philadelphia: Falmer Press.

Merriam, B.S. (1998). Qualitative research and case study applications in education. San Francisco, CA: Jossey-Bass.

Ontario Ministry of Education. (2005). Many Roots, Many Voices. Toronto, ON: Queen’s Printer for Ontario.

Ontario Ministry of Education. (2007). Building bridges to success for First Nation, Métis, 
and Inuit Students. Toronto, ON: Aboriginal Education Office.

Ontario Ministry of Education. (2007). Ontario First Nation, Métis, and Inuit Education Policy Framework. Toronto, ON: Aboriginal Education Office.

Onwuegbuzie, A.J., \& Johnson, R.B. (2006). The validity issue in mixed research. Research in the Schools, 13(1), 48-63.

Onwuegbuzie, A.J., Witcher, A.E., Collins, K.M., Filer, J.D., Wiedmaier, C.D., \& Moore, C.W. (2007). Students' perceptions of characteristics of effective college teachers: A validity study of a teaching evaluation form using a mixed-methods analysis. American Educational Research Journal, 44(1), 113-160.. http://dx.doi.org/10.3102/0002831206298169

Reynolds, H. (2001). An indelible stain? The question of genocide in Australia's history. Ringwood, Vic: Penguin.

Reynolds, R.J. (2002). The search for relevance and identity: The education and socialization of Australian Aboriginal students. International Education, 31(2), 18-32.

Santaro, N. (2007). Outsiders and others: Different teachers teaching in culturally diverse classrooms. Teachers and Teaching: Theory and Practice, 13(1), 81-97.

Santaro, N., \& Allard, A. (2005). Re-examining identities: Working with diversity in the preservice teaching experience. Teaching and Teacher Education, 21(7), 863-873. http://dx.doi.org/10.1016/j.tate.2005.05.015

Shkedi, A., \& Nisan, M. (2006). Teachers' cultural ideology: Patterns of curriculum and teaching culturally valued texts. Teachers College Record, 108(4), 687-725. http://dx.doi.org/10.1111/j.1467-9620.2006.00665.x

Sleeter, C.E. (1993). How white teachers construct race. In C. McCarthy and W. Crichlow (Eds.), Race, identity and representation in education (pp. 157-171). London: Routledge.

Smyth, J. (2001). Critical politics of teachers' works: An Australian perspective. New York: Peter Lang.

Solomon, R.P., \& Levine-Rasky, C. (2003). Teaching for equity and diversity: Research to practice. Toronto, ON: Canadian Scholars Press.

Sparks, S. (2000). Classroom and curriculum accommodations for Native American students. Intervention in School and Clinic, 35(5), 259-263. http://dx.doi.org/10.1177/105345120003500501

Statistics Canada. (2003). 2001 census: Analysis series - Aboriginal peoples of Canada: A demographic profile. Ottawa, Canada: Author.

Strauss, A., \& Corbin, J. (1990). Basics of qualitative research: Grounded theory procedures and techniques. Newbury Park, CA: Sage.

Swanson, S. (2003). Motivating learners in northern communities: Native literacy and learning of Aboriginal perspectives. Canadian Journal of Native Education, 27(1), 16-25. 


\section{Macrothink

Tashakkori, A., \& Teddlie, C. (2003). Validity issues in mixed methods research: Calling for an integrative framework. Paper presented at the annual meeting of the American Educational Research Association, San Francisco.

Wearmouth, J., Glynn, T., \& Berryman, M. (2005). Perspectives on student behaviour in schools. London: Routledge.

Yazzie, T. (1999). Culturally appropriate curriculum: A research-based rationale. In K. Swisher \& J. Tippeconnic (Eds.), Next steps: Research and practice to advance Indian education (pp. 83-106). Charleston, NC: Appalachia Educational Laboratory.

\section{Copyright Disclaimer}

Copyright reserved by the author(s).

This article is an open-access article distributed under the terms and conditions of the Creative Commons Attribution license (http://creativecommons.org/licenses/by/3.0/). 